\title{
A method to evaluate the adaptability of photovoltaic energy on urban facades
}

\author{
Esclapés Jover, F.J. ${ }^{(1)}$; Ferreiro Prieto, I. ${ }^{(2)}$; Piera Llodrá, J. ${ }^{(3)}$; Teller, J. ${ }^{(4)}$ \\ Department of Graphic Expression and Cartography, University of Alicante (Spain) \\ (1) javier.esclapes@ua.es \\ (2) ignacio.ferreiro@ua.es \\ (3) jp129@alu.ua.es \\ LEMA, University of Liege (Belgium) \\ (4) Jacques.teller@ulg.ac.be
}

\begin{abstract}
Solar simulation and evaluation tools are essential for the design of novel energy and environmental strategies. To date, a number published studies in this area focused on the analysis of flat roofs and small urban areas. This paper presents a method, based on Geographic Information Systems (GIS), for defining the potential of photovoltaic solar energy over urban façades. The method enables the generation of 3D solar maps from two standard data sources, namely cadastral cartography and data on solar irradiance registered by the Spanish State Meteorological Agency (AEMET, for its initials in Spanish).
\end{abstract}

A series of charts have been generated relating the urban and solar geometries as a result of the numerical model. The charts permit the study of the optimal parameters for the photovoltaic integration over façades. Using this method, we demonstrate that the most suitable façades are those included within orientation angles of $\pm 30^{\circ}$ and with obstruction angles $\leq 45^{\circ}$.

In addition, a study conducted over a representative urban area of Madrid is discussed as an example of the applicability of the discussed methodology. The results indicate that $7.22 \%$ of the area's façades are usable for the installation of photovoltaic solar energy, according to current Spanish regulations. Some $3,853 \mathrm{MWh}$ of electric energy could be generated by photovoltaic panels, which would satisfy $45.6 \%$ of the energy consumed within the analysed zone.

Finally, the adequacy of the Spanish Technical Edification Code (CTE, for its initials in Spanish), defining thresholds regarding the usability of photovoltaic energy, has been tested both theoretically and through the case study. Our study concludes that this regulation hinders the architectural integration of photovoltaic devices given the strict usability thresholds adopted.

\section{Keywords}

Solar radiation, Irradiation on facades, Shading factor, Buildings integration photovoltaic, GIS 


\begin{tabular}{|llll|}
\hline \multicolumn{2}{|l|}{ Nomenclature } & & \\
$A_{\text {usable }}$ & usable façade area $\left(\mathrm{m}^{2}\right)$ & $h_{\text {oh }}$ & obstruction hour angle $\left({ }^{\circ}\right)$ \\
$a v$ & track width $(\mathrm{m})$ & $h_{\text {sun }}$ & height of the sunlit façade $(\mathrm{m})$ \\
$a v_{s}$ & solar track width $(\mathrm{m})$ & $h_{\text {shade }}$ & height of the shading façade $(\mathrm{m})$ \\
$B$ & direct irradiance $\left(\mathrm{Wh} / \mathrm{m}^{2}\right)$ & $P O I$ & losses due orientation and inclination $\left(\mathrm{Wh} / \mathrm{m}^{2}\right)$ \\
$B_{o}$ & extra-atmospheric irradiance $\left(\mathrm{Wh} / \mathrm{m}^{2}\right)$ & $P S$ & losses due to shading $\left(\mathrm{Wh} / \mathrm{m}^{2}\right)$ \\
$D$ & diffuse irradiance $\left(\mathrm{Wh} / \mathrm{m}^{2}\right)$ & $P_{\text {usable }}$ & binary coefficient, usable façade \\
$D_{c}$ & circumsolar diffuse irradiance $\left(\mathrm{Wh} / \mathrm{m}^{2}\right)$ & $S$ & Insolation $(\mathrm{h})$ \\
$D_{i}$ & isotropic diffuse irradiance $\left(\mathrm{Wh} / \mathrm{m}^{2}\right)$ & $\alpha$ & angle of orientation of the photovoltaic sensor $\left({ }^{\circ}\right)$ \\
$E$ & produced energy $(\mathrm{Kw})$ & & angle of inclination of the photovoltaic sensor $\left({ }^{\circ}\right)$ \\
$F_{h}$ & height factor on façade & & latitude $\left({ }^{\circ}\right)$ \\
$F_{\text {usable }}$ & façade usable percentage area $(\%)$ & $\lambda$ & correcting solar angle $\left({ }^{\circ}\right)$ \\
$G$ & global irradiance $\left(\mathrm{Wh} / \mathrm{m}^{2}\right)$ & & height or elevation, solar coordinate $\left({ }^{\circ}\right)$ \\
$h_{o}$ & obstruction angle $\left({ }^{\circ}\right)$ & & azimuth, solar coordinate $\left({ }^{\circ}\right)$
\end{tabular}

\section{Introduction}

Building-Integrated Photovoltaics (BIPV) represent an energetically and environmentally recognised strategy with a promising future (1) (2) (3). It is one of the priorities for the European Union to achieve energy efficiency in buildings (Directive 31/2010/UE). Specific photovoltaic systems offer many possibilities for an improved architectural integration thanks to the correct combination of design and technology (semi-transparencies, colours, etc.), as well as the possible synergetic effects between functionalities such as solar protection, glare protection and the bioclimatic effects of natural ventilation (4). Still, in addition to issues related to grid parity and the necessary consumption model (5) (6), photovoltaic systems should still provide the necessary consumer confidence in order to become a constructive element within the buildings themselves.

In urban areas, it is estimated that façades comprise $60-80 \%$ of building surfaces (7). Despite this fact, a number of studies on the architectural integration of solar energy have largely focused on flat roofs (8) (9) (10) (11) (12). In order to encourage the architectural integration of photovoltaic energy on façades, this article considers a simple procedure to rapidly determine its applicability within large urban areas, based on inputs readily available from standard data sources, namely cadastre survey and meteorological records.

A key aspect of the problem resides in the shading of the façades, which makes the estimation of solar irradiance particularly difficult. There are different computational models for this estimation over partially shaded surfaces (13) (14) (15) (16) (17) (18). One controversial aspect of these models is the computation of the diffuse component of radiation (19) (20) (21) (22). Some of these equations have been implemented in software tools such as Radiance (17) or Townscope (23). These equations allow to perform studies on an urban area for any period of time. The main limitation of such equations is that they require importing a 3D virtual model previously generated with CAD (Computer Assisted Design), which makes the study of wide urban areas difficult.

As an alternative, a numerical model has been developed that directly relates the solar irradiance with the urban geometry, further allowing a solar analysis over the façades of large urban surfaces based on a GIS (2D). As initial inputs, this model use the cadastral cartography and solar irradiance data recorded by the Spanish State Meteorological Agency (AEMET). The validation of this model has been performed through the comparison of results with the solar simulation software Townscope. 
Given the potential of this methodology and with the aim of defining the concept of usable surface area, this work has adopted the limits established by the regulating directive for the architectural integration of photovoltaic systems (Technical Code for Edification, CTE). This allowed us to use the method as a tool for the analysis and revision of the current regulation.

The discussed method has an international scope of applicability, although application could depend on the target country, provided that it is adapted to the specific format of historical data on weather, cadastral cartography and edification regulation. Considering these, our method aims to be a survey tool for solar simulation, with the capability of generating large solar maps and demonstrating the potential of photovoltaic architectural integration on façades in large urban areas.

The present article is organised in eight sections. Sections 2-4 present the development of the method (parametric model for urban geometries, insolation, solar irradiance calculation and energy losses). Section 5 then summarizes the usability thresholds fixed by the technical building standards for photovoltaic energy in Spain. Section 6 outlines the implementation of the method within a GIS, emphasizing the assumptions that were adopted so as to provide all required geometric variables required by our model. Based on these, Section 7 presents and discusses theoretical irradiance charts derived from the method and an application of the GIS tool to a case study in Madrid. The last section outlines the conclusions with a special interest in the practical effects of the technical standards adopted in Spain.

\section{Parametric model of urban geometry}

A parametric model of urban geometry serves as the basis for the development of the proposed method. The overall method has two objectives. First, it has to propose a simple and direct equation that relates insolation and solar irradiance with the urban geometry; second, it should allow the generation of 3D results for façades beginning with a 2D system (cadastral cartography), which makes it suitable for its implementation in a GIS.

According to these objectives, urban geometries have been modelled through streets, characterized by given orientation and obstruction factors. In order to optimise the number of nodes used in the simulation model, the height of the façade is divided in 10 horizontal bands. All calculations have been performed for 11 nodes (P0, P1, P2,.., P10) centred on the façade and related to the numerical model through the height factor (). The value of this factor ranges from 1 for node P0 to 0 for node P10. The width of the façade is assumed to be infinite, with the latitude $(\varphi)$ depending on the characteristics of the city under consideration. The parameters of the numerical model are then defined as follows: 
- Track width $(a v)$, distance defined by the cartography itself.

- Solar track width $\left(a v_{s}\right)$, distance defined by the cartography and the sun's position (eq. 6).

- Height of the façade that generates shade $\left(h_{\text {shade }}\right)$, vertical distance of the façade that obstructs sunlight beams and generates shade.

- Orientation $(\alpha)$ of the façade, angle formed by the normal of the sunlit façade and the south orientation, defined by the cartography itself.

- Sun's azimuth $\left(\Psi_{s}\right)$, angle defined by the sun's position.

- Angle of obstruction $\left(h_{o}\right)$, defined by the cartography itself (eq. 7).

- Angle of solar corrector $(\lambda)$, angle formed by the façade's orientation $(\alpha)$ and the sun's azimuth $\left(\Psi_{S}\right)$. To derive the equation, the model considers all cases that can occur through the day. Therefore:

- Obstruction hour angle $\left(h_{o h}\right)$, defined by the cartography itself and the point of study. The value of $h_{o h}$ changes during the course of the day and for each node in the façade according to the following equation:

\section{Insolation over façades}

The insolation $(S)$ over façades is critical to estimate the produced energy as well as the computation of the photovoltaic installation performance in an urban area. There is no uncertainty in this variable because there are no weather parameters involved in its computation. Therefore, the presented calculations are a mere trigonometric relation between solar, geometric and urban parameters. In this way, solar coordinates and urban cartographic parameters will be used to perform the calculation.

The solar irradiance intensity varies significantly throughout the day, being greater around midday. Therefore, it is very important to know the time at which the node is receiving sunlight or is in shade. Thus, the insolation for a particular time will be calculated first, repeating the calculation for each tenth of an hour fraction and then converting it to hourly, daily, and annual data.

The insolation value is based on several conditions that are mathematically defined to determine whether a node is exposed to sunlight or in shade.

Condition 1: If the building in front of the façade blocks the sunlight, then the corresponding node is in shade. 
As can be observed in the figure, the relation between the angle $h_{\text {oh }}$ and the solar height determines whether the façade points are in the sun or shade.

Condition 2: If the façade itself blocks the sunlight, the nodes are all in shade. For certain orientations and at particular moments throughout the day, the azimuth can overpass the façade's tracking line and generate shade over the façade.

Condition 3: If the sun does not cross the horizon, the nodes will not receive sunlight. That is to say, the solar height must be greater than 0 .

After exploring all geometric possibilities and unifying these three conditions, the insolation value is calculated for each node as follows:

where $S\left(P_{n}\right)$ is a binary variable acquiring a value of 1 when the node is exposed to sunlight and 0 when it is in shade.

To obtain the hourly insolation $\left(S_{h}\left(P_{n}\right)\right)$, the procedure is applied 10 times over 6-minute intervals for each of the nodes, assuming the hourly insolation as the arithmetic average of the resulting values. Similarly, once the hourly data are obtained, the data are converted to daily, monthly, and annual values for their analysis through the corresponding summations and arithmetic averages.

\section{Solar irradiance over façades}

As has been mentioned previously, there are many methods to estimate the solar irradiance on an inclined surface. These methods have been tested in different locations worldwide and exhibit many similarities, but they mainly differ in the estimation of the diffuse component of the irradiance. The equations that better adapt to the characteristics of the model in the study have been selected among all of the available numerical models. The following requirements must be fulfilled:

- The numerical system must separate the global irradiance into its direct, diffuse and reflected components.

- For the appropriate models, it is necessary to distinguish between sunlit and shaded surfaces. The estimation of the diffuse component is a key aspect.

- The irradiance estimation must be based on horizontal global irradiance data, a variable recorded by the Spanish State Meteorological Agency (AEMET) as is the case of most meteorological agencies.

- The model must allow the irradiance to be broken down in its hourly values. The irradiance intensity greatly varies throughout the day, so it is important to know the time slot in which shading occurs.

The representative days of each month have been used to estimate the monthly average solar irradiance. For every month in a year, there is one particular day when the daily irradiance equals the average monthly irradiance (24). 
The steps that must be followed to calculate the solar irradiance over façades are presented below by means of a phase diagram. The involved equations are included in the annex of the present article.

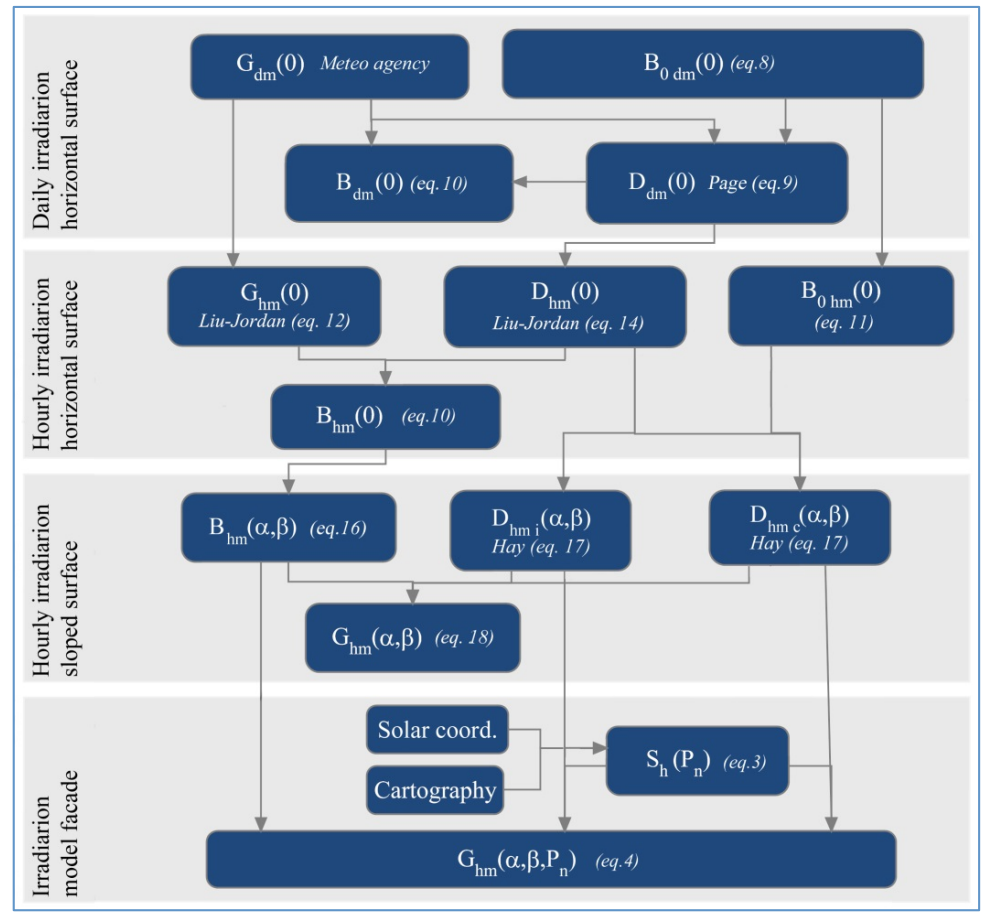

Fig. 3 -Scheme for the estimation of the solar irradiance on façades.

\section{Initial data}

The horizontal global irradiance $\left(G_{d}(0)\right)$ data supplied by the AEMET are used as a starting point. By applying the corresponding divisions and arithmetic averages, the data are filtered and processed to obtain the monthly average global irradiance per day for the 12-month year period $\left(G_{d m}(0)\right)$. The calculation of the monthly average of the daily extra-atmospheric irradiance over a horizontal surface $\left(B_{0 \mathrm{dm}}(0)\right)($ eq. 8$)$ is used; the input for this calculation solely requires knowledge of the solar coordinates. The equations described in the previous section are used to calculate the hourly isolation ( $\mathrm{Sh}(\mathrm{Pn}))$.

\section{Daily solar irradiance over a horizontal surface}

The model of Page (25) has been used to calculate the diffuse component over a horizontal surface $\left(D_{d m}\right.$ (0)). This model corresponds to one of the most well-known and scientifically tested equations (eq. 9). The direct component of the solar irradiance $\left(B_{d m}(0)\right)$ can then be deduced from the total global irradiance incident on a horizontal surface (eq. 10).

\section{Daily to hourly data conversion}

The next step is the conversion to hourly values of the monthly average extra-atmospheric irradiance over a horizontal surface $\left(B_{0 \mathrm{hm}}(0)\right)$ (eq. 11). The Liu-Jordan equation (26) is used for the hourly conversion of the global irradiance, including the improvements made by Collares-Pereira and Rabl (1) (eq. 12, eq. 13). 
In addition, the Liu-Jordan model (26) (eq. 14, eq. 15) is used for the calculation of the hourly diffuse component $\left(D_{h m}(0)\right)$.

\section{Hourly solar irradiance over an inclined surface}

The monthly average of the hourly direct irradiance over an inclined surface $\left(B_{h m}(\alpha, \beta)\right)$ is calculated through trigonometric considerations starting with the value for a horizontal surface (eq. 16). The Hay model (19) is used to calculate the diffuse component $\left(D_{h m}(\alpha, \beta)\right)$ because it is a complete model and conforms to the requirements of the discussed methodology. The model assumes an anisotropic behaviour of the irradiance and further separates the diffuse component into its isotropic and circumsolar components, treating this last component in a directional manner (eq. 17).

Similar to the calculations over horizontal surfaces, the global irradiance over an inclined surface $\left(G_{h m}\right.$ $(\alpha, \beta))$ is the sum of its three components, given that the reflected irradiance should also be included here (eq. 18). Still for the proposed method, the reflected component has been ignored because the intensities obtained in the first simulations over façades were negligible.

\section{Irradiance over façades}

Throughout the day, building façades in metropolitan areas can be exposed to sunlight, shaded, or partially shaded. Following the steps of the proposed model, the monthly average of the global hourly irradiance $\left(G_{h m}\left(\alpha, \beta, P_{n}\right)\right)$ for each façade node can be obtained from the following equation:

(eq. 4)

This equation estimates the global irradiance over totally shaded surfaces by suppressing the direct component and the diffuse circumsolar component from the general equation, as proposed by other authors such as Tregenza (13) or Driz (16).

Finally, once the hourly global irradiance data are obtained, it is important to convert them to daily, monthly, and annual values for their analysis in each node. This step can be calculated through the corresponding summations and arithmetic averages.

\subsection{Orientation and inclination losses}

To maximise the solar radiation incident on the target surface, sun rays have to strike the surface at rightangles for the longest possible period of time. Given that façades have a fixed orientation and inclination (with practically no possibility of movement), the losses due to orientation and inclination angles constitute a first element to be taken into account in the utility analysis of façades for photovoltaic energy.

The monthly average losses caused by daily orientation and inclination $\left(P O I_{d m}(\alpha, \beta)\right)$ are defined through the difference between the annual average of the global daily maximum irradiance) and the monthly average of the global daily irradiance received $\left(G_{d m}(\alpha, \beta)\right)$ for a particular place and under sunlit conditions. Regarding the annual values, the average losses caused by daily orientation and inclination $\left(P O I_{d a}(\alpha, \beta)\right)$ are estimated through the calculation of the corresponding arithmetic average.

The orientation factor $\left(F O I_{d a}(\alpha, \beta)\right)$ corresponds to the losses specifically due to orientation and inclination of the receptors. It is used to obtain a more versatile variable to analyse the optimal installation parameters independent of the received solar radiation. It corresponds to the percentage of annual losses due to orientation and inclination with respect to the maximal global irradiance.

\subsection{Losses caused by shading}

In line with the developed method, the monthly average of daily losses caused by shading is calculated for each façade node $\left(P S_{d m}\left(\alpha, \beta, P_{n}\right)\right)$. This average is defined as the difference between the monthly 
average of the global daily irradiance free of shading $\left(G_{d m}(\alpha, \beta)\right)$ and the monthly average of daily irradiance for each node that is partially shaded $\left(G_{d m}\left(\alpha, \beta, P_{n}\right)\right)$. In this way, it is possible to obtain annual values through the corresponding calculation of arithmetic averages.

The shading factor $\left(F S_{d m}\left(\alpha, \beta, P_{n}\right)\right)$ corresponds to the percentage of losses due to shading with respect to the global irradiance that would strike on the same surface with no shading. This factor allows for a more detailed analysis of the impact of shading on the facades.

\section{Estimation of the potential integration of solar photovoltaic systems in façades.}

In order to evaluate the potential architectural integration of a photovoltaic system, it is necessary to define which part of the façade's surface area can be considered usable. This is a complex and changeable concept given that there are many variables that take part in the modelling equations: the technology (performance, losses, etc.), geographic location, economic considerations, fiscal or direct stimuli etc.

In Spain utility values are governed by a regulation (CTE) that defines fixed thresholds that have been included in the building standards. Considering these threshold values within our model hence constituted an opportunity to analyse and discuss the provision of building standards on the architectural integration of photovoltaic systems on façades. The maximal losses for the installation of photovoltaic systems indicated by the CTE in its directive HE5 are summarized in table 1. It can be seen that these requirements vary according to the type of installation, so as to offer more flexibility (lower level of constraints) in the case of a due architectural integration when compared with a general installation that solely aims at maximizing the irradiance.

\begin{tabular}{lccc} 
Case & q (orientation and inclination) & $\mathbf{q}^{\prime}$ (shades) & q"' (total) \\
\hline General (type I) & $10 \%$ & $10 \%$ & $15 \%$ \\
Superposition (type II) & $20 \%$ & $15 \%$ & $30 \%$ \\
Architectural integration (type III) & $40 \%$ & $20 \%$ & $50 \%$
\end{tabular}

Table 1 - Losses limits. CTE

Three cases are hence distinguished in the regulation: 1) the modules are not integrated within any envelope component and constitute a detached featured "fixed" upon the building, 2) architectural superposition "when the positioning of the solar panels is parallel to the building envelope, where the horizontal arrangement aimed at favouring the self-cleaning of the modules is not accepted within this concept, 3) architectural integration "when the modules satisfy a double function, energetic and architectural, and substitute conventional constructive elements or are constituent elements of the architectural composition".

In all cases, three conditions must be observed: orientation and inclination losses, shading losses, and total losses. These should lie below the thresholds with respect to the values obtained with optimal orientation and inclination without shading.

Regarding the numerical method discussed in previous sections, a binary variable repressing the usable node $\left(N_{\text {usable }}\left(P_{n}\right)\right)$ has been defined to assess the potential integration for each stretch of the façade. This variable is obtained through the following equation:

resulting in a value of 1 when the node is usable and 0 when it is not. The factors $q, q$ ', and $q$ ', are specified in Table 1. 
Given that for some applications it will be necessary to know the total utility potential of the façade, a variable $\left(F_{\text {usable }}\right)$ has been defined. It is obtained through the arithmetic average of the calculated values on each of the façade nodes. This value can be expressed as a percentage and will be analysed for the three installation types stipulated in the Spanish regulation.

Another significant aspect is the usable façade area $\left(A_{\text {usable }}\right)$ for the installation of solar photovoltaic systems, which can be obtained based on the knowledge of the urban geometry. This value is produced by multiplying the height of the sunlit façade $\left(h_{\text {sun }}\right)$, the width of the sunlit façade $\left(\mathrm{a}_{\text {sun }}\right)$, and the percentage of usable façade area $\left(F_{\text {usable }}\right)$.

Additional outputs can then be estimated once the usable surface area for the installation of the photovoltaic systems has been determined. It is possible to calculate the produced energy $(E)$ for each part of the façade (eq. 19) (28) or the amount of avoided $\mathrm{CO}_{2}$ emission, assuming that $0.6 \mathrm{~kg}$ of $\mathrm{CO}_{2}$ is avoided per produced kWh (29). All these equations should be solved for the three installation types considered in the CTE.

\section{GIS implementation}

This is the last step of the proposed methodology and describes an algorithm that allows the generation of solar maps based on the potential architectural integration of photovoltaic systems over façades. The algorithm uses the cadastral cartography and the historic data on the solar irradiance recorded by the AEMET.

Several libraries of the gvSIG software have been used during the development of this phase. gvSIG is a powerful GIS package (open source and free) that provides solutions to all of the needs related to the management of geographical information. All algorithms were developed in Java and used the Sextante library (an open source library of algorithms for spatial analysis) included in gvSIG.

Prior to the solar analysis, it is important to prepare the cartographic data and obtain the initial data required by each of the proposed calculation steps. All gathered data are stored in a particular database for a later use. The performed measurement steps are specified below:

- Filtering of the cadastral cartography data (provided in shape file format). Given the wide and diverse information that is in the cartographic data, those polygons that are not suitable for the study are discarded. The façades that are the subjects of study are also defined in this step.

- Acquisition of the sunlit façade height $\left(h_{\text {sun }}\right)$. This step makes use of the height information contained in each subparcel provided by the cadastral database; this value is multiplied by $3.5 \mathrm{~m}$ as a standard measure per floor, resulting in the total height of the sunlit façade.

- Acquisition of the shaded façade height $\left(h_{\text {shade }}\right)$. The difficulty of determining this value relies on knowing what elements will generate shades on the façade. To this end, an algorithm to locate the façades that generate shade based on trigonometric calculations has been developed; the resulting heights are also stored by this algorithm, and the height of a shaded façade is obtained through the arithmetic average of these heights

- Acquisition of the track width $(a v)$. This value is obtained through trigonometry, measuring the length of the orthogonal line drawn from the midpoint of the façade to the intersection with the shaded façade.

- The heights of the sunlit and shaded buildings have been set to be equal in the proposed basic algebraic model (Section 2) on which the computational models operate. This seldom happens in reality. In consequence the algorithm performs an adjustment of the output data once the computations have been executed. In this way, the results are adapted to realistic cartographic data. 
Once the algorithm has been executed, it generates KML files that contain the output data. Keyhole Markup Language (KML) is a language specifically designed to represent 3-dimensional geographic data). The resulting files can be processed with free visualisers such as Google Earth and ArcGIS explorer, which facilitates accessing the obtained results.

\section{Results}

\subsection{Theoretical irradiance charts}

Several graphs have been generated from the numerical model as part of the research work. These show the insolation, the received global irradiance, and the usability potential of façades in photovoltaic systems installations in compliance with the CTE.

The comparative results of the analysis are shown for two critical inclination values: the façade orientation $\left(\beta=90^{\circ}\right)$ and the optimal orientation. Our purpose is to contrast the behaviour of the solar irradiance along the façade.

The city of Madrid (Spain) $\left(\varphi=40^{\prime} 2^{\circ}\right.$ and $\left.\beta_{o p t}=30^{\circ}\right)$ has been chosen as a case study for the input data. Given its geographic location, the values in the graphs can be considered applicable to the whole Iberian Peninsula.

Figures 4 and 5 highlight the annual behaviour of the global daily irradiance for different façade heights. 


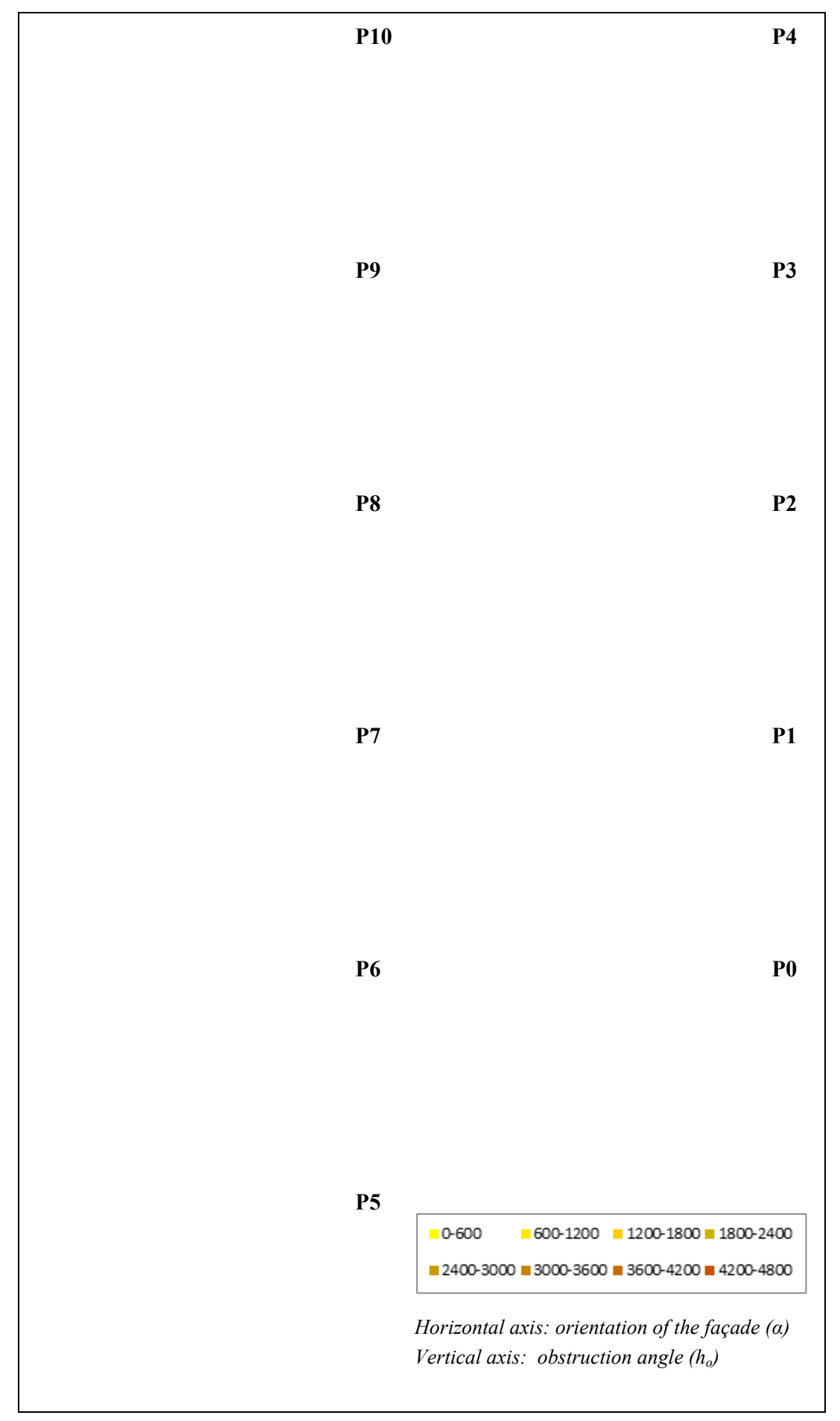


Fig. 4 - Annual average daily global irradiance $\left(\mathrm{Wh} / \mathrm{m}^{2}\right)$ over a facade for $\beta=90^{\circ}$ in Madrid.

P10

P4

P9

P3

P8

P2

P7

P1

P6

P0

P5 $=0-600 \quad=600-1200=1200-1800=1800-2400$
$=2400-3000=3000-3600=3600-4200=4200-4800$
$=4800-5400 \backsim 5400-6000=6000-6600 \square 6600-7200$

Horizontal axis: orientation of the façade ( $\alpha$ ) Vertical axis: obstruction angle $\left(h_{o}\right)$ 
By comparing the amount of received irradiance for the two inclinations, we observe a $40-50 \%$ reduction on the irradiance value for $\beta=90^{\circ}$ with respect to the optimal inclination. The value of the maximum irradiance obtained is $2957 \mathrm{Wh} / \mathrm{m}^{2}$ (for $\beta=90^{\circ}$ ) and $4978 \mathrm{Wh} / \mathrm{m}^{2}$ (for $\beta_{\mathrm{opt}}=30^{\circ}$ ). A similar behaviour is observed for both inclinations, and a clear adverse effect of the shades between the buildings is observed. From node P8 to node P0, shading corresponds to almost $80 \%$ of the façade's height. As expected, the optimal orientation occurs along the southerly direction $\left(0^{\circ}\right)$ in all cases, although orientations between $-30^{\circ}$ and $+30^{\circ}$ are quite reasonable for most nodes. Outside these limits, the decrease of irradiance is higher and progressive. As the obstruction angle increases, the received global irradiance steadily decreases, with the largest decrease occurring for obstruction angle values above $40^{\circ}$.

Surprisingly, the results for a vertical inclination $\left(\beta=90^{\circ}\right)$ are zero for the three types of installation. Thus, the CTE prevents the architectural integration over the façade due to restrictive limits imposed over the loss values related to the orientation and inclination. The following table shows the obtained values for $F_{\text {usable }}$ under favourable conditions $\left(\alpha=0^{\circ}, h_{0}=40^{\circ}\right)$. It can be seen that it is mainly the threshold on orientation and inclination that impedes the installation of integrated panels in a vertical plane.

$\begin{array}{lcccccccccccc} & \boldsymbol{P}_{0} & \boldsymbol{P}_{\boldsymbol{1}} & \boldsymbol{P}_{2} & \boldsymbol{P}_{3} & \boldsymbol{P}_{4} & \boldsymbol{P}_{5} & \boldsymbol{P}_{6} & \boldsymbol{P}_{7} & \boldsymbol{P}_{8} & \boldsymbol{P}_{9} & \boldsymbol{P}_{10} & \boldsymbol{F}_{\text {usable }} \\ \text { FOI } & 42.5 & 42.5 & 42.5 & 42.5 & 42.5 & 42.5 & 42.5 & 42.5 & 42.5 & 42.5 & 42.5 & - \\ \text { FS } & 42.6 & 37.0 & 29.5 & 26.9 & 16.2 & 7.6 & 4.4 & 2.5 & 1.3 & 0.5 & 0.3 & - \\ \mathbf{N}_{\text {usable }} \text { ( I) } & 0 & 0 & 0 & 0 & 0 & 0 & 0 & 0 & 0 & 0 & 0 & \mathbf{0} \% \\ \mathbf{N}_{\text {usable }} \text { ( II) } & 0 & 0 & 0 & 0 & 0 & 0 & 0 & 0 & 0 & 0 & 0 & \mathbf{0} \% \\ \mathbf{N}_{\text {usable }} \text { ( III) } & 0 & 0 & 0 & 0 & 0 & 0 & 0 & 0 & 0 & 0 & 0 & \mathbf{0} \%\end{array}$

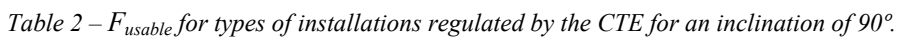

In contrast, excellent results have been obtained for the optimal inclination $\left(\beta_{o p t}=30^{\circ}\right)$, as can be observed in the following graphs representing the percentage of usable façade surface area for the different types of installations considered by the CTE. It should still be noted that graphs for types II and III installations are somehow theoretical given the difficulty to integrate photovoltaic systems with a $30^{\circ}$ inclinations within facades.

Fig. 6 - Percentage of usable façade $\left(F_{\text {usable }}\right)$ for type I, II and III installations. Horizontal axis: façade orientation $(\alpha)$; vertical axis: obstruction angle (ho).

The orientations with larger usable surfaces do not necessarily correspond to the southerly direction $\left(0^{\circ}\right)$ but to the following ranges: $-30<\alpha<+30$ (type I), $-40<\alpha<+40$ (type II), and $-45<\alpha<+45$ (type III). Within these ranges, the southerly orientation is the one that receives most annual irradiance. 
Considering the façades with a minimal annual usable surface area of at least $50 \%$ of the total surface (from P10 to P5) to be acceptable, the optimal obstruction angle would be as follows: ho $\leq 45^{\circ}$ (type I), ho $\leq 50^{\circ}$ (type II), and ho $\leq 55^{\circ}$ (type III).

To conclude this analysis, it should be emphasised that, according to the CTE regulation (for type I photovoltaic installation), the optimal inclination of the collector for the most suitable urban geometry is in the range of $\pm 30^{\circ}$ for an obstruction angle $\leq 45^{\circ}$. Once again, it should be stressed that, although type III (architectural integration) is the most suitable category, this geometry represents a very hypothetical option, given the difficulty to duly integrate photovoltaic systems with a $30^{\circ}$ inclination as an architectural component..

The thresholds imposed by the CTE on losses hence appear excessively restrictive for an architectural integration of photovoltaic systems on façades. Some products with a great level of integration (curtain walls, windows, awnings, etc.) could never comply with the regulation. The thresholds defined by the regulation should be more flexible, if one of its aim is effectively to foster a better integration of photovoltaic systems as an architectural component.

\subsection{Case study}

The proposed method has been applied to a representative area of Madrid. The area corresponds to a section of the Recoletos de Madrid district, in particular to the set of buildings located at the following coordinates: $40^{\circ} 25^{\prime} \mathrm{N}, 3^{\circ} 40^{\prime} \mathrm{O}$. The selected zone is composed of 6 urban blocks that occupy a total surface area of 10 ha. The area includes 2,597 apartments (cadastral information) with a total façade surface of 298,411.4 $\mathrm{m}^{2}$. Considering an average electric consumption of 3,250 $\mathrm{kWh}$ per floor (occupied on average by 2.71 people), the total energy consumption would lie around $8,440 \mathrm{MWh}$ per year for the selected area. Average electric consumptions have been obtained from the Spanish National Statistics Institute (INE, for its initials in Spanish).

The algorithm is executed after importing the cartographic data within gvSIG (processing time: 24 '), generating all solar maps (KML format) with the results for the selected area. Similarly, as discussed in the previous section, the solution is obtained for two critical inclinations, the façade orientation and the optimal orientation. The most relevant results are discussed below.

The annual average global irradiance ranges between 467-2964 $\mathrm{Wh} / \mathrm{m}^{2}$ for the façade incline and between $913-4989 \mathrm{Wh} / \mathrm{m}^{2}$ for the optimal inclination. After comparing the results, it is possible to observe that the values for an inclination $\beta=90^{\circ}$ are approximately $40 \%$ less than the values corresponding to the optimal inclination.
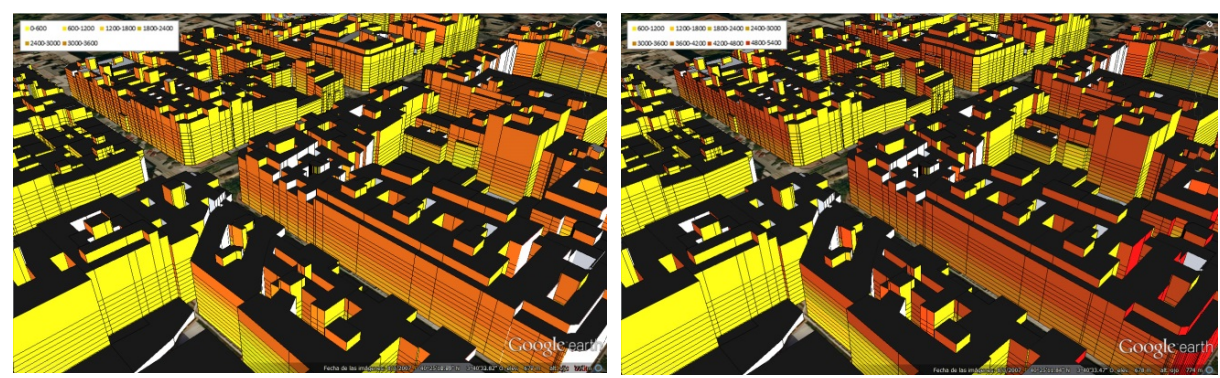

Fig. 7 - Global irradiance for an inclination of $90^{\circ}$ and for an optimal inclination, respectively. 
On the other hand, the solar map demonstrates the negative effect caused by shading in both cases, where $60-80 \%$ of the façade heights are greatly affected. The adverse effect of the losses caused by façade orientation is also observed, although it is less evident for orientations closer to the southerly direction.

As previously discussed, the method does not find any usable façade surface area corresponding to a façade inclination of $\left(90^{\circ}\right)$, given the strict limits set by the CTE for architectural integration.

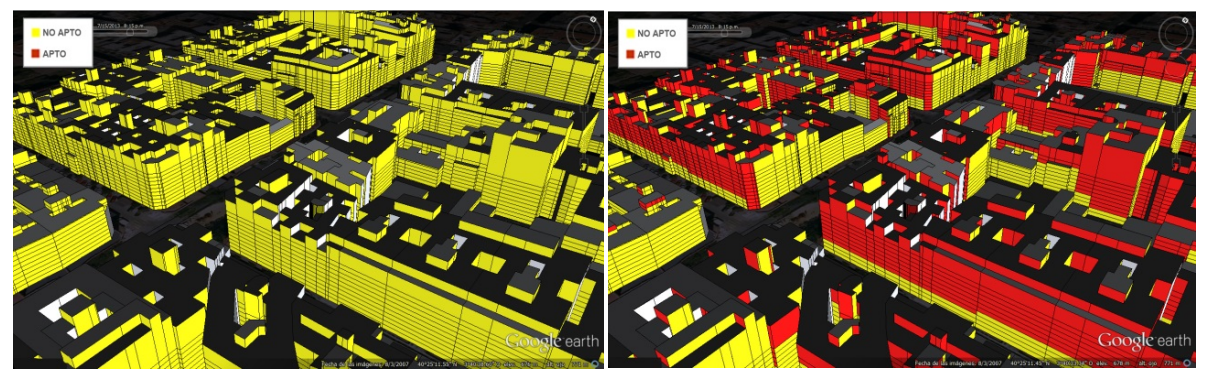

Fig. 8 - Potential of architectural integration for an inclination of $90^{\circ}$ and for an optimal inclination (type III), respectively. The potential architectural integration for each installation proposed by the CTE has been analysed for the case of optimal inclination $\left(\beta_{\text {opt }}=30^{\circ}\right)$. To this end, the gvGIS analysis tools have been used, which allow one to obtain the most relevant data on the following: potential architectural integration, generated energy, and avoided $\mathrm{CO}_{2}$ emissions for all façades under consideration $\left(298411.4 \mathrm{~m}^{2}\right)$. These results are shown in the table below.

\begin{tabular}{|c|c|c|c|c|c|c|}
\hline & \multicolumn{2}{|c|}{ Potential of integration } & \multicolumn{2}{|c|}{ Energy } & \multicolumn{2}{|c|}{ Avoid $\mathrm{CO}_{2}$} \\
\hline & $\left(\mathrm{m}^{2}\right)$ & $(\%)$ & daily (kWh) & $\begin{array}{l}\text { Annual } \\
\text { (MWh) }\end{array}$ & daily (Kg) & $\begin{array}{c}\text { Annual } \\
\text { (Tn) }\end{array}$ \\
\hline Type I & 21,545 & $7 ’ 22$ & 10,558 & 3,853 & 6,334 Kg & 2,311 \\
\hline Type II & 38,316 & $12^{\prime} 84$ & 14,142 & 5,161 & $8,485 \mathrm{Kg}$ & 3,079 \\
\hline Type III & $47,311.2$ & $15^{\prime} 85$ & 16,558 & 6,043 & $9,934 \mathrm{Kg}$ & 3,625 \\
\hline
\end{tabular}

Both the annual average of daily-generated energy and the avoided $\mathrm{CO}_{2}$ emissions are estimated from the sum of the obtained values for each of the usable bands of the façades. It has been assumed that photovoltaic generators will be installed on the entire usable surface area.

According to the results obtained and the usability of the analysed area, it is possible to estimate that the architectural integration could satisfy conditions to obtain a $71.5 \%$ energy consumption for a type III installation, $61.1 \%$ for a type II, and $45.6 \%$ for a type I installation. As in the previous section, the results for typical installations (type I) have been taken as a reference.

\section{Conclusions}

A novel method for the estimation of insolation and solar irradiance has been proposed that directly relates variables of solar irradiance with urban geometry.

This is the first GIS-based method that has been developed for the study of the potential integration of photovoltaic systems on façades and has allowed the study of large urban surfaces. The method has been capable of generating data such as the usable surface area for the installation of photovoltaic systems, generated energy, and avoided $\mathrm{CO}_{2}$ emissions.

The executed algorithm provides several files containing three-dimensional cartography data associated with annual and monthly data on insolation, solar irradiance, losses related to shading, orientation, and 
inclination, as well as the integration potential of photovoltaic systems and the energy generated on the façades.

The generated solar maps demonstrate the incidence of sunlight over irregular zones such as inner courtyards or bevelled corners. These inaccuracies can be corrected by including such conditions in the computational algorithm. On the other hand, the large size of the resulting files can hinder the visualisation, which suggests that reducing the data density corresponding to 3-dimensional building information by discarding polygons and substituting the set of polygons by orthophotos could be beneficial.

The set of graphics generated in each of the phases of the developed method contribute to the representation of the sun rays annual behaviour on the façades, in which is possible to observe the adverse effect of shading on the façades. These graphics may represent a useful source of information for researchers and professionals in the photovoltaic sector.

With respect to the revision of the CTE, we conclude that their provisions are not compatible with the architectural integration of photovoltaic systems on facades. The limits on losses imposed by the regulation are extremely restrictive. These limits do not allow in any case the installation with a $90^{\circ}$ inclination. This forces the installation of photovoltaic devices with certain slope, further restricting aesthetic aspects of the photovoltaic integration on a façade. Our assessment recommends a justified update of the limits of orientation and inclination-related losses.

Undoubtedly, both the proposed method and the set of generated graphics could be a starting tool for the development of new procedures and research projects on environmental and energy policies.

\section{Referencias}

1. Caamaño, E. Edificios Fotovoltaicos Conectados a Red Eléctrica: Características y Posibilidades Energéticas. Madrid : Instituto de Energía Solar, Universidad Politécnica de Madrid, 2000. PhD thesis.

2. Oliver, M. y Jackson, T. Energy and economic evaluation of building-integrated photovoltaics. Energy, 2001, Vol. 26, págs. 431-439.

3. International Energy Agency (IEA). Potential for Building Integrated Photovoltaics. 2002. PSPV - T7-4.

4. Martín, N. Integración de la Energía Fotovoltaica en Edificios. Sevilla (España) : Promotora General de Estudios, 2012. ISBN: 9788495693686.

5. European Photovoltaic Industry Association (EPIA). Solar Photovoltaics Competing in the Energy Sector - On the road to competitiveness. Brussels : s.n., 2011.

6. Asociación de la Industria Fotovoltaica. La situación FV en el Mundo y en España. s.I. : Asociación de la Industria Fotovoltaica, 2011.

7. Esclapés, F.J. Adaptabilidad de la Energía Solar Fotovoltaica sobre fachadas en entornos urbanos. Alicante : Universidad de Alicante, 2012. PhD thesis.

8. Garrido, A., y otros, y otros. Aplicaciones de los sistemas de información geográfica para la implantación de energias renovables en entornos urbanos. Mapping, 1994, Vol. 19, 76 - 81. 
9. An evaluation of the potential of building integrated photovoltaics in Canada. Pelland, S. y Poissant, Y. Montréal, Canada : 31st Annual Conference of the Solar Energy Society of Canada (SESCI), 2007.

10. Sombras imposibles: la utilización de los sistemas de información geográfica (SIG) para generar modelos de iluminación de áreas urbanas. Escolano, S. Cáceres : IX Conferencia Iberoamericana de Sistemas de Información Geográfica, 2004.

11. ESRI. GIS for Renewable Energy. Redlands, USA : ESRI, 2007.

12. ISES-AP - 3rd International Solar Energy Society Conference. Pellegrino, M., y otros, y otros. Sydney, Australia : s.n., 2008.

13. Tregenza, P. y S., Sharples. Daylighting algorithms. s.I. : ETSU, 1993. Vol. S1350.

14. Tregenza, P. y Wilson, M. Daylighting: Architecture and Lighting Design. s.I. : Routledge, 2011. 9780419257004

15. Robinson, D. y Stone, A. A new simplified urban-sensitive daylight model. Solar Energy, 2005.

16. Drif, M., Perez, P.J., Aguilera, J., Aguilar, J.D. A new estimation method or irradiance on a partially shaded PV generator in grid-connected photovoltaic systems. Renewable Energy, 2008, Vol. 33, págs. 2048-2056.

17. Mardaljevic, J. y Rylatt, M. Irradiation mapping of complex urban enviroments: an imagebased approach. Energy and Buildings, 2003, Vol. 35, págs. 27-35.

18. Quachning, V. y Hanitsh, R. Irradiance calculation on shaded surfaces. Sol Energy, 1998, Vol. 62(5), págs. 369-375.

19. Hay, J.E. Calculation of monthly mean solar radiation for horizontal and inclined surfaces. Solar Energy, 1979, Vol. 23, pág. 301.

20. Muneer, T. Solar radiation and daylight models. Edinburgh : Napier University, 2004. ISBN: 9780750659741.

21. Perez, R., Seals, R. y Michalsky, J. Modelling daylight availability and irradiance components from direct and global irradiance. Solar Energy, 1990, Vol. 44, págs. 271-289.

22. Gueymard, C. An anisotropic solar irradiance model for tilted surfaces and its comparison with selected engineering algorithms. Solar Energy, 1987, Vol. 38, 367-386.

23. Teller, J. y Azar, S. Townscope II-A computer system to support solar access decisionmaking. Solar Energy, 2001, Vol. 70, págs. 187-200.

24. Lorenzo, E. Radiación solar y dispositivos fotovoltaicos. Madrid : Universidad Politécnica de Madrid, 2006. Vol. 2. 8495693313. 
25. Page, J.K. The estimation of monthly mean value of daily short wave irradiation on vertical and inclined surfaces from sunshine records for latitudes 60N to 40ㅇ. Department of Building Science, University of Sheffield, UK.

26. Liu, B.Y.H y Jordan, R.C. The interrrelation ship and characteristics distribution of direct, diffuse and total solar radiation. Solar Energy, 1960, Vol. 4 (3), págs. 1-19.

27. Pereira, M.C. y Rabl, A. The average distributio of solar radiation - correlations between diffuse and hemispherical and between daily and hourly insolation values. Solar Energy, 1979, Vol. 22, pág. 155.

28. Instituto de la diversificación y ahorro de la energía IDAE. Instalaciones de Energía Solar Fotovoltaica. Madrid : s.n., 2011.

29. European Photovoltaic Industry Association. Solar Energy V. Brussels : s.n., 2008.

30. Konarka. Konarka Power Plastic. [En línea] 2012. http://www.konarka.com/.

31. Townscope. Web oficial software Townscope. [En línea] http://www.townscope.com/.

32. Hofierka, J. y Kanuk, J. Assessment of photovoltaic potential in urban areas using opensource solar radiation tools. Renewable Energy, 2009, Vol. 34, 2206-2214.

33. City of Boston. RENEW BOSTON SOLAR. [En línea] http://gis.cityofboston.gov.

34. Dirección General del Catastro. Site oficial. [En línea] http://www.catastro.meh.es/.

35. Shaviv, E. y Yezioro, A. Analyzing mutual shading amont buildings. [ed.] Sol Energy. Sol Energy, 1997, Vol. 59, págs. 83-88.

36. Non-Uniformity in Incident Solar Radiation over the Facades of High Rise Buildings. Marsh, A. Eindhoven, The Netherlands : PLEA 2004 - The 21th Conference on Passive and Low Energy Architecture, 2004.

\section{Appendix A. Equations}

(eq.6) Solar track width:

(eq.7) Obstruction angle:

(eq.8) Monthly average of extra-atmospheric irradiance over a horizontal surface area:

where is the length of the day ( $24 \mathrm{~h}$ ) and is the sun angle (degrees) for the representative days in each month

(eq.9) Monthly average of the daily diffuse irradiance over a horizontal surface:

(eq.10) Monthly average of the daily global irradiance over a horizontal surface: 
(eq.11) Monthly average of the extra-atmospheric hourly irradiance over a horizontal surface:

where,, $\mathrm{y}$, and are the angles at the beginning and end of the defined hour in radians.

(eq.12) (eq.13) Hourly conversion of global irradiance:

where ; .

(eq.14) (eq.15) Hourly conversion of the diffuse component:

(eq. 16) Monthly average of the direct hourly irradiance over an inclined surface:

(eq. 17) Monthly average of the diffuse hourly irradiance over an inclined surface:

where $F$ is the clarity factor :

(eq. 18) Monthly average of the global hourly irradiance over an inclined surface:

(eq. 19) Energy generated:

where $P_{m p}$ is the peak power of the generator, $P R$ is the energy performance of the installation, and $\mathrm{G}_{\mathrm{CEM}}$ is the irradiance under standard conditions $\left(1000 \mathrm{Wh} / \mathrm{m}^{2}\right)$. 